\title{
Predicting Variation on Void Ratio Deposition Influenced by Hydraulic Conductivity and Porosity Impact in Heterogeneous Silty and Peat Soil Formation
}

\author{
Jaja GWT and Eluozo SN* \\ Department of Civil Engineering, Nigeria \\ *Corresponding author: Eluozo SN, Department of Civil Engineering, Faculty of Engineering, Nigeria
}

Submission: 眥 November 16, 2018; Published: 眥 November 27, 2018

\begin{abstract}
The study predicts the variation of void ratios on hydraulic conductivity and porosity impact for silty and peat sand deposition. The rate conductivity and porosity were considered in the system to predominantly pressure the deposition of void ratio on silty and peat sand formation, such structural deposition experienced predominant heterogeneity in the study location, the deposition reflected unconsolidated deposition that should be evaluated in fundamental analysis of engineering properties of soil for design of foundation, these condition made the study imperative, several experts may always apply the conventional system to generate parameters for void ratio, but the compressive analysis in most time are not gotten, but the analytical techniques applied were able to develop model that can determine the comprehensive deposition of void within the intercedes of the formation, the study has developed another conceptual approach to thoroughly monitor void ratio within silty and peat soil formation.
\end{abstract}

Keywords: Predicting void ratio hydraulic conductivity; Silty and peat sand

\section{Introduction}

current study on nature of soil formations and its engineering stress-strain response Indicate that the soil performs as a collection of scale-level-dependent skeletons arranged in a Particular manner [1-3]. However, several studies have mentioned that the physical nature of silty sand is entirely different from that of clean sand [1,37]. They recognized that the undrained residual shear strength (Sus) response depends effectively on the void ratio as a state parameter. It is also anticipated that the global void ratio (e) cannot represent the amount of particle contacts in the sand-silt mixture samples [812]. As the void ratio and proportion of the coarse-grained soil or fine-grained soil changes, the nature of their microstructures also changes $[13,14]$. Due to a large grain size distribution range and availability of voids larger than some grains, at low fines contents, some of the finer grains may remain inactive and swim in the void spaces without affecting or contributing to the force chain [15-17]. Therefore, it is quite important to use new index parameters such as the intergranular $[2,18,19]$

\section{Theoretical background}

$$
\begin{aligned}
& K \Phi \frac{d^{2} e}{d x^{2}}=D V \frac{d e}{d x}+V_{(X)} \frac{d e}{d x} \\
& K \Phi \frac{d^{2} e}{d x^{2}}-\left(D V+V_{(X)}\right) \frac{d e}{d x} \\
& \text { Let } e=\sum_{n=0}^{\infty} a_{n} x^{n}
\end{aligned}
$$

$$
\begin{aligned}
& e^{1}=\sum_{n=1}^{\infty} \boldsymbol{a}_{n} x^{n-1} \\
& e^{\mathbb{1}}=\sum_{n=2}^{\infty} n(n-1) a_{n} x^{n-2} \\
& K \Phi \sum_{n=2}^{\infty} n(n-1) a_{n} x^{n-2}=\left(\begin{array}{ll}
D & \left.+V_{(X)}\right) \sum_{n=1}^{\infty} a_{n} x^{n-1}
\end{array}\right.
\end{aligned}
$$

Replace $n$ in the $1^{\text {st }}$ term by $n+2$ and in the $2^{\text {nd }}$ term by $n+1$, so that we have;

$$
\begin{aligned}
& K \Phi \sum_{n=2}^{\infty}(n+2)(n+1) a_{n+2} x^{n}=\left(D_{V}+V_{(X)}\right) \sum_{n=0}^{\infty}(n+1) a_{n+1} x^{n} \\
& \text { i.e. } K \Phi(n+2)(n+1) a_{n+2}=\left(D_{V}+V_{t}\right)(n+1) a_{n+1} \\
& a_{n+2}=\frac{\left(D_{V}+V_{(X)}\right)(n+1) a_{n+1}}{K \Phi(n+2)(n+1)} \\
& a_{n+2}=\frac{\left(D_{V}+V_{(X)}\right) a_{n+1}}{K \Phi(n+2)} \\
& \text { for } n=0, a_{2}=\frac{\left(D_{V}+V_{(X)}\right) a_{1}}{2 K \Phi} \\
& \text { for } n=1, a_{3}=\frac{\left(D_{V}+V_{t}\right) a_{2}}{3 D}=\frac{\left(D_{V}+V_{(X)}\right)^{2} a_{1}}{2 D \bullet 3 D} \\
& \text { for } n=2 ; a_{4}=\frac{\left(D_{V}+V_{(X)}\right) a_{0}}{4 D}=\frac{\left.\left(D_{V}+V_{(X)}\right)\right)}{4 D} \bullet \frac{\left(D_{V}+V_{(X)}\right) a_{1}}{3 D \bullet 2 D}=\frac{\left(D_{V}+V_{(X)}\right)^{3} a_{1}}{4 D \bullet 3 D \bullet 2 D}
\end{aligned}
$$




$$
\begin{gathered}
\text { for } n=3 ; a_{5}=\frac{\left(D_{V}+V_{(X)}\right) a_{4}}{5 D}=\frac{\left(D_{V}+V_{(X)}\right)}{5 D \bullet 4 D \bullet 3 D \bullet 2 D} \\
\text { for } n ; a_{n}-\frac{\left(D_{V}+V_{t}\right)^{n-1} a_{1}}{K \Phi^{n-1} n !} \\
C(x)=a_{0}+a_{1} x+a_{2} x^{2}+a_{3} x^{3}+a_{4} x^{4}+a_{5} x^{5}+\ldots \ldots a_{n} x_{n} \\
=a_{0}+a_{1} x+\frac{\left(D_{V}+V_{(X)}\right) a_{1} x^{2}}{2 ! D}+\frac{\left(D_{V}+V_{(X)}\right) a_{2} x^{3}}{3 ! D^{2}}+\frac{\left(D_{V}+V_{(X)}\right) a_{1} x^{4}}{4 ! D^{3}}+\frac{\left(D_{V}+V_{(X)}\right) a_{1} x^{5}}{5 ! D^{4}}+\ldots \\
C(x)=a_{0}+a_{1}\left[x+\frac{\left(D_{V}+V_{(X)}\right) x^{2}}{2 ! D}+\frac{\left(D_{V}+V_{(X)}\right) x^{3}}{3 ! D^{2}}+\frac{\left(D_{V}+V_{(X)}\right) x^{4}}{4 ! D^{3}}+\frac{\left(D_{V}+V_{(X)}\right) x^{5}}{5 ! D^{4}}\right] \\
C(x)=a_{0}+a_{1} \ell
\end{gathered}
$$

Subject equation (16) to the following boundary conditions

$C(o)=0$ and $C(o)=H$

$$
\begin{aligned}
& C(x)=a_{0}+a_{1} \ell^{\frac{\left(D_{V}+V\right)}{K \Phi} x} \\
& C(o)=a_{0}+a_{1}=0 \\
& \text { i.e. } a_{0}+a_{1}=0
\end{aligned}
$$

$C^{1}(x)=\frac{\left(D_{V}+V_{(X)}\right)}{2 ! D} a_{1} \ell^{\frac{\left(D_{V}+V_{(X)}\right)}{D} x}$

$C^{1}(o)=\frac{\left(D_{V}+V_{(X)}\right)}{2 ! D} a_{1}=H$

$a_{1}=\frac{H D}{D_{V}+V_{(X)}}$

Substitute (18) into equation (17)

$a_{1}=a_{0}$

$\Rightarrow a_{0}=\frac{-B}{D_{V}-V_{(X)}}$

Hence the particular solution of equation (16) is of the form:

$$
\begin{aligned}
& C(x)=\frac{H D}{D_{V}+V_{(X)}}+\frac{H D}{D_{V}+V_{(X)}} \ell^{\frac{\left(D_{V}+V_{(X)}\right)_{x}}{D}} \\
& \Rightarrow C(x)=\frac{H D}{D_{V}+V_{(X)}}\left[\ell^{\frac{\left(D_{Y}-V_{(X)}\right)}{K \Phi} x}-1\right]
\end{aligned}
$$

\section{Materials and Method}

Standard laboratory experiment where performed to monitor the void Ratio deposition at different formation, the soil deposition of the strata were collected in sequences base on the structural deposition at different study area, this samples collected at different location generate variation at different depth producing different deposition strata void ratio base on their litho structures the experimental result are applied to compare with theoretical values for model validation [20-22].

\section{Result and Discussion}

Results and discussion are presented in Table 1-10 including graphical representation of void ratio at different litho structures. Figure 1-10 shows the deposition of void ratios in linear structural setting as presented in the figures, the depositions of the void ratios within silty and peat formations explain the rate of heterogeneity in deposition of void within the intercede of the formation, the exponential setting from all the graphical representation express the rate of the litho structures of the soil in terms geomorphology effect and geochemistry in the strata depositions, the geological reflection of the location were also observed in the study to pressure the structural setting of the strata. The derived model solution were applied to monitor the depositions as in numerical and analytical setting through simulation, the study has observed the variation of the void from the generated predictive values thus compared with experimental values, it is concluded that the deposition of silty and peat soil in deltaic environment were based on the rate of heterogeneity level of disintegration of the predominant deposited porous rock in deltaic locations. The validation of the simulation developed favourable fits, the derived solution has predicted the void within silty and peat soil formation. The determination of void ratios is basic principle of engineering properties of soil for design of various foundation thus the rate consolidation including settlement of different condition in soil engineering.

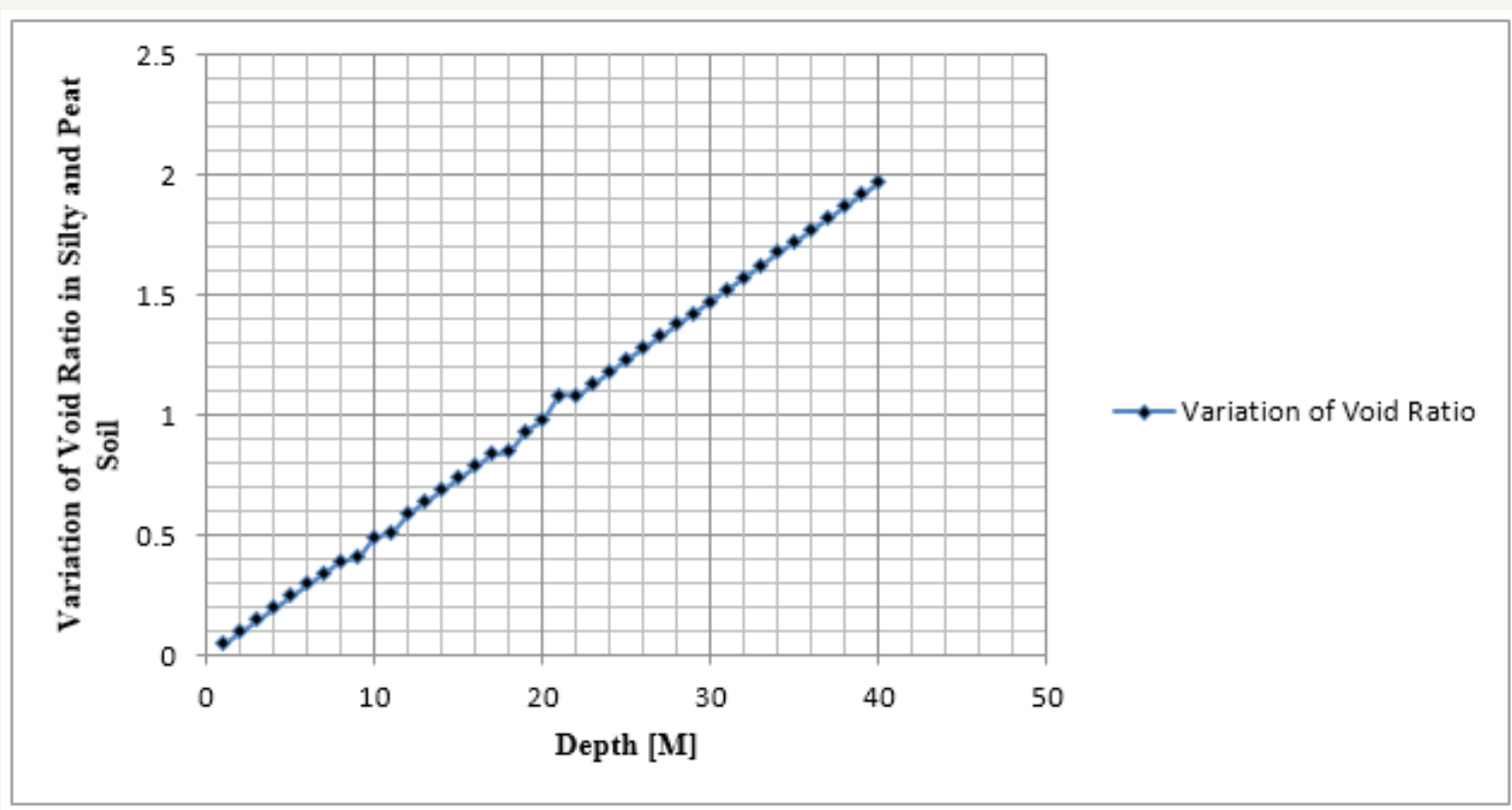

Figure 1: Predictive values of void ratio at different depths. 


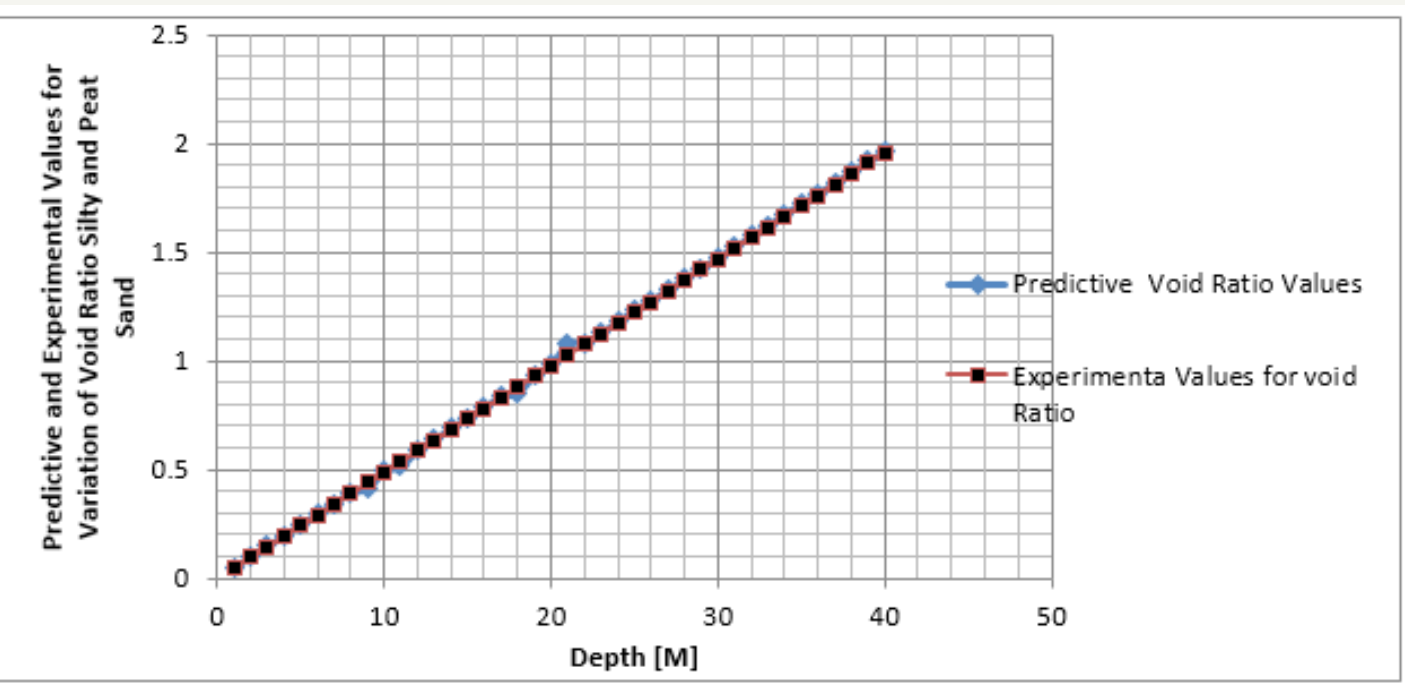

Figure 2: Comparison of predictive and measured values of void ratio at different depth.

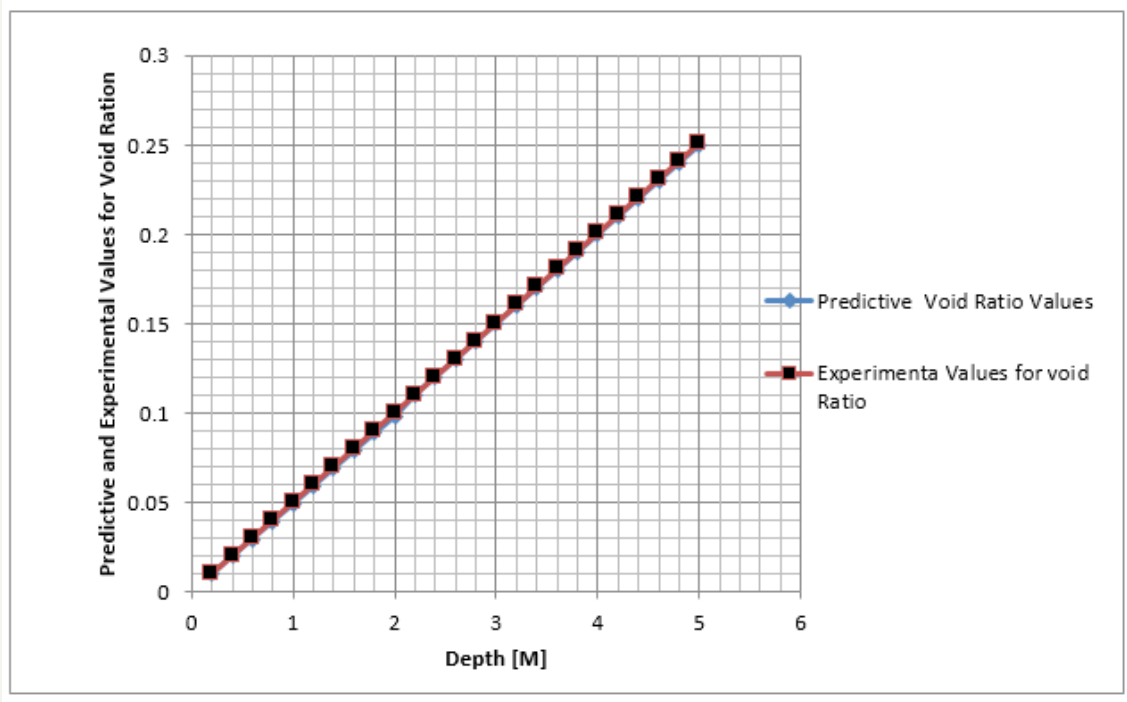

Figure 3: Comparison of predictive and measured values of void ratio at different depth.

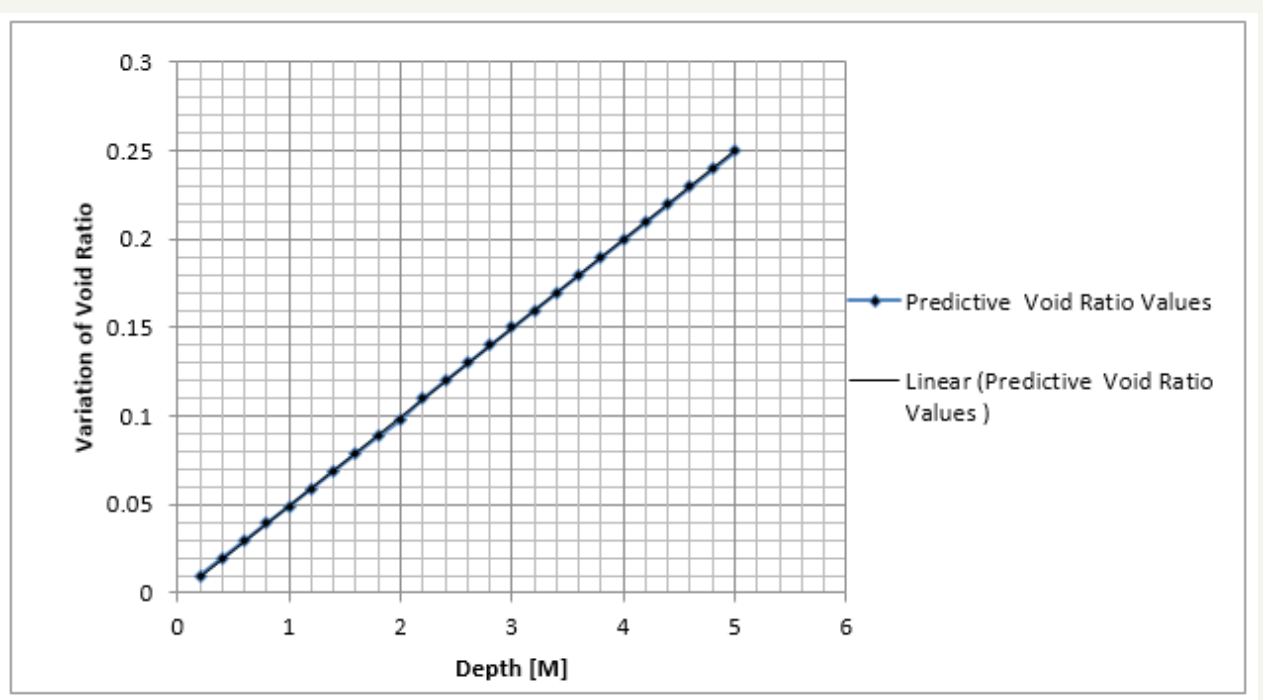

Figure 4: Predictive values of void ratio at different depths. 


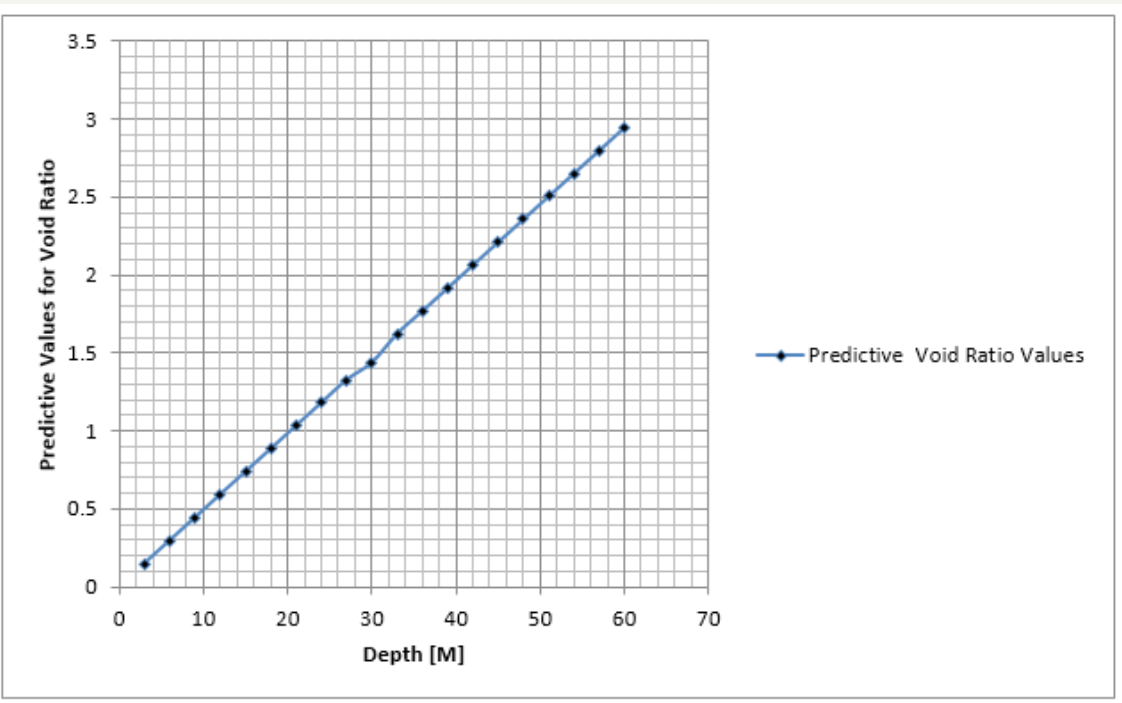

Figure 5: Predictive values of void ratio at different depths.

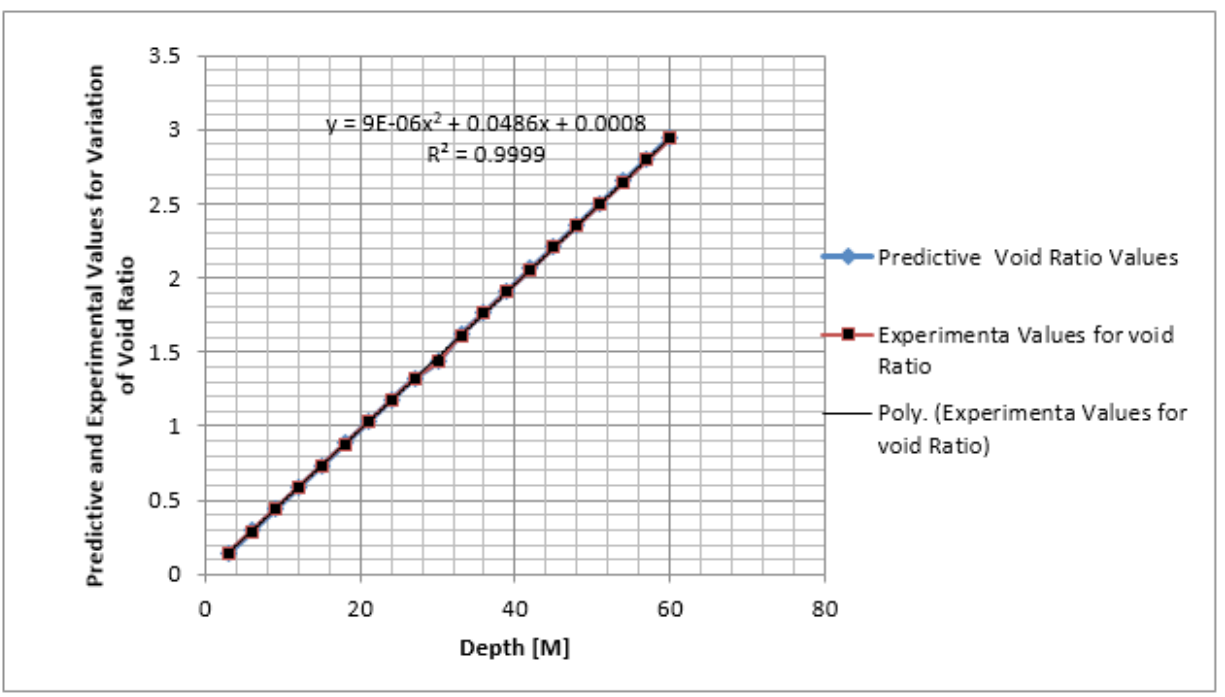

Figure 6: Comparison of predictive and measured values of void ratio at different depth.

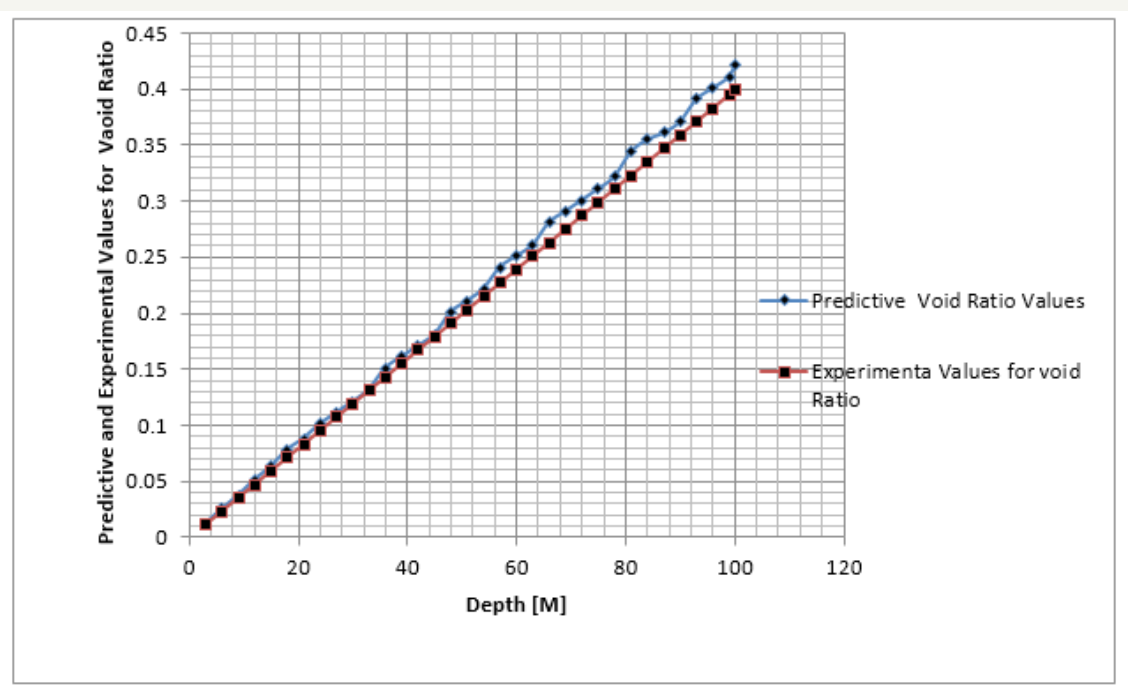

Figure 7: Comparison of predictive and measured values of void ratio at different depth. 


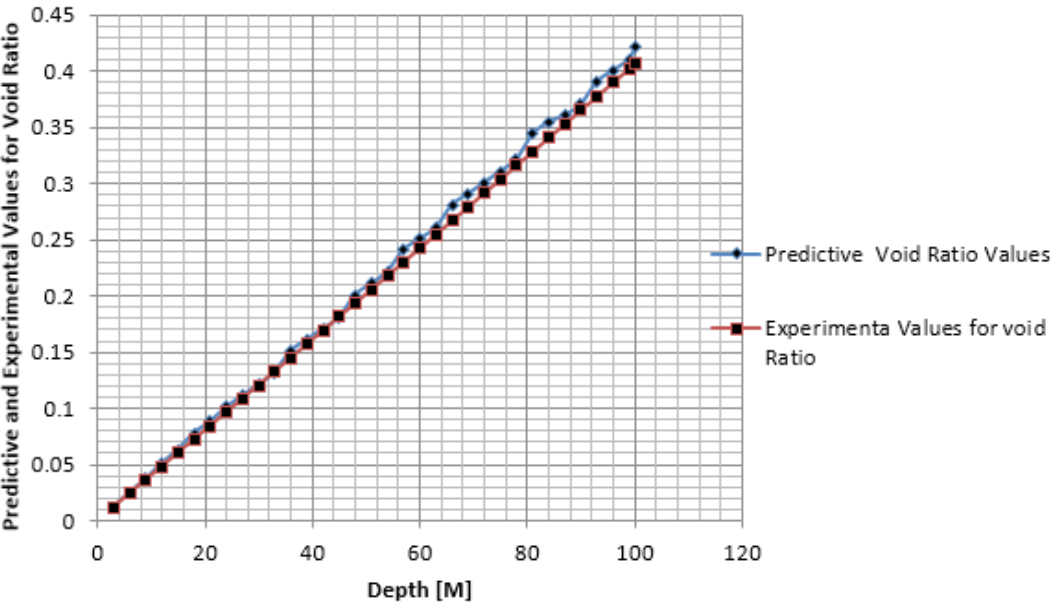

Figure 8: Comparison of predictive and measured values of void ratio at different depth.

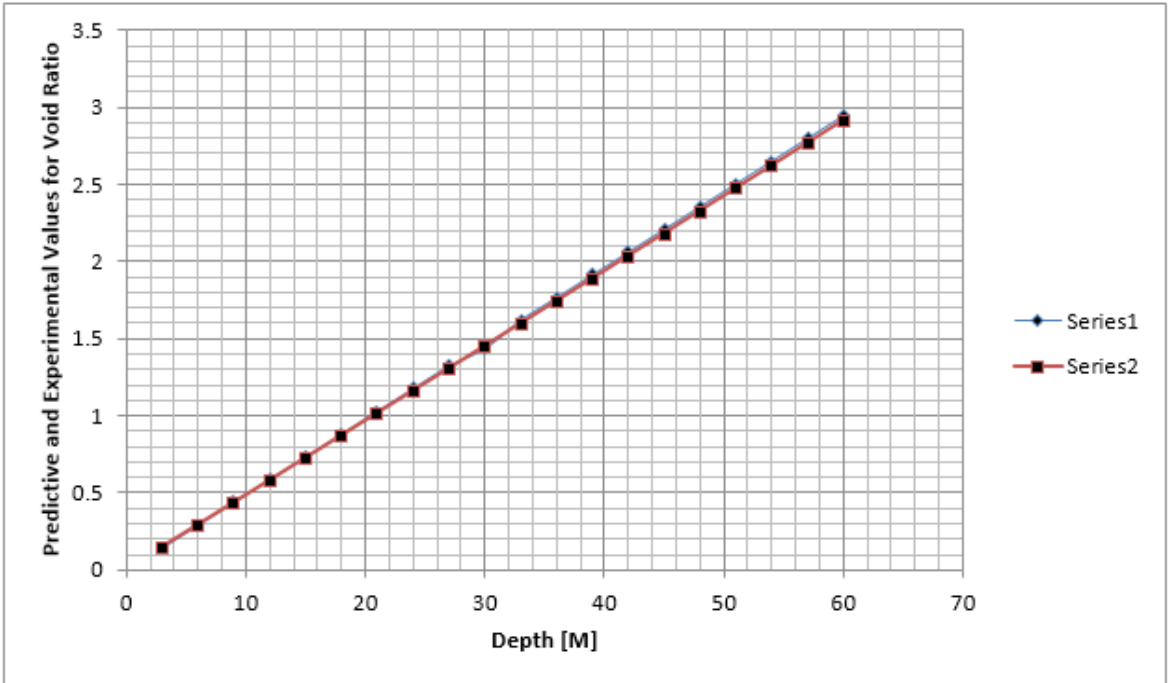

Figure 9: Comparison of predictive and measured values of void ratio at different depth.

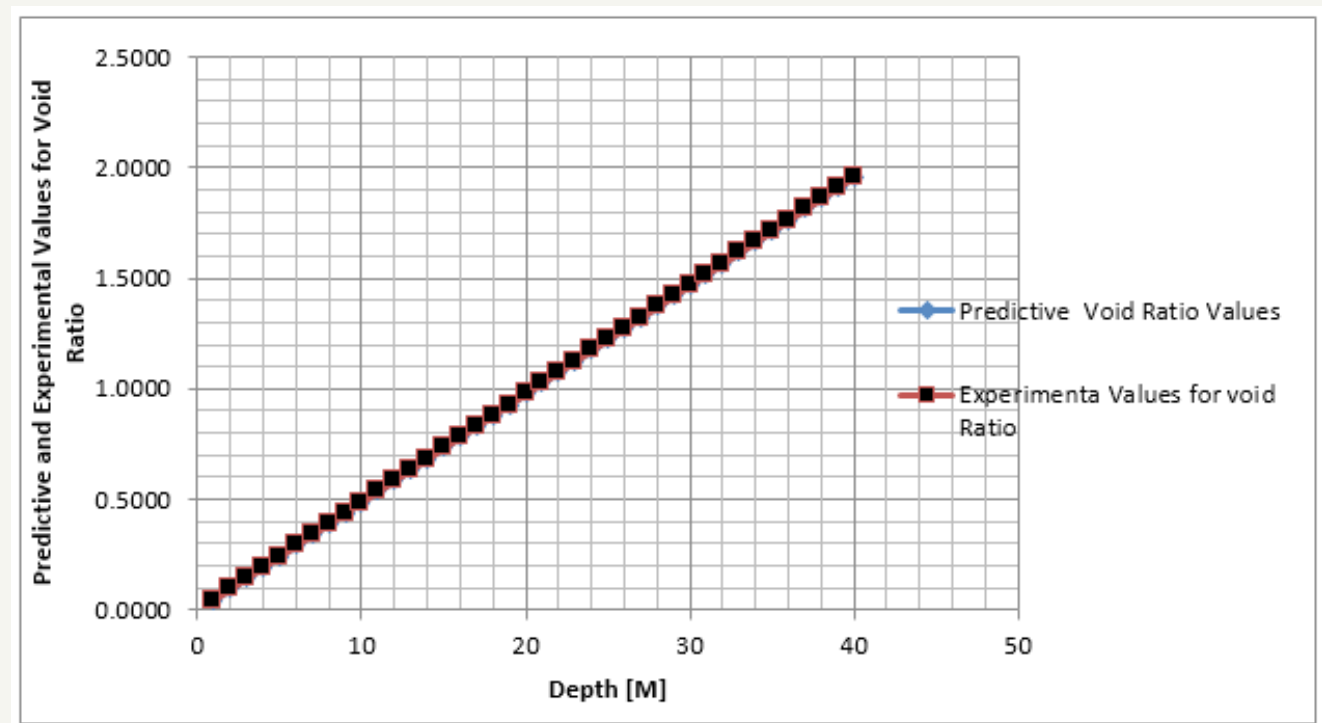

Figure 10: Comparison of predictive and measured values of void ratio at different depth. 
Table 1: Predictive values of void ratio at different depths.

\begin{tabular}{|c|c|}
\hline Depth [M] & Variation of Void Ratio \\
\hline 1 & 0.0491 \\
\hline 2 & 0.0982 \\
\hline 3 & 0.1476 \\
\hline 4 & 0.1968 \\
\hline 5 & 0.2461 \\
\hline 6 & 0.2962 \\
\hline 7 & 0.3441 \\
\hline 8 & 0.3936 \\
\hline 9 & 0.4123 \\
\hline 10 & 0.4921 \\
\hline 11 & 0.5142 \\
\hline 12 & 0.5904 \\
\hline 13 & 0.6396 \\
\hline 14 & 0.6888 \\
\hline 15 & 0.7381 \\
\hline 16 & 0.7872 \\
\hline 17 & 0.8364 \\
\hline 18 & 0.8523 \\
\hline 19 & 0.9348 \\
\hline 20 & 0.9841 \\
\hline 21 & 1.0822 \\
\hline 22 & 1.0821 \\
\hline 23 & 1.1316 \\
\hline 24 & 1.1808 \\
\hline 25 & 1.2341 \\
\hline 26 & 1.2792 \\
\hline 27 & 1.3284 \\
\hline 28 & 1.3776 \\
\hline 29 & 1.4268 \\
\hline 30 & 1.4761 \\
\hline 31 & 1.5252 \\
\hline 32 & 1.5744 \\
\hline 33 & 1.6236 \\
\hline 34 & 1.6778 \\
\hline 35 & 1.7221 \\
\hline 36 & 1.7712 \\
\hline 37 & 1.8204 \\
\hline 38 & 1.8696 \\
\hline 39 & 1.9188 \\
\hline 40 & 1.9681 \\
\hline
\end{tabular}

Table 2: Comparison of predictive and measured values of void ratio at different depth.

\begin{tabular}{|c|c|c|}
\hline Depth [M] & $\begin{array}{c}\text { Predictive Void Ratio } \\
\text { Values }\end{array}$ & $\begin{array}{c}\text { Experimental Values for void } \\
\text { Ratio }\end{array}$ \\
\hline 1 & 0.0491 & 0.0460 \\
\hline 2 & 0.0982 & 0.0950 \\
\hline 3 & 0.1476 & 0.1440 \\
\hline 4 & 0.1968 & 0.1930 \\
\hline 5 & 0.2461 & 0.2420 \\
\hline 6 & 0.2962 & 0.2910 \\
\hline 7 & 0.3441 & 0.3400 \\
\hline 8 & 0.3936 & 0.3890 \\
\hline 9 & 0.4123 & 0.4380 \\
\hline 10 & 0.4921 & 0.4870 \\
\hline 11 & 0.5142 & 0.5360 \\
\hline 12 & 0.5904 & 0.5850 \\
\hline 13 & 0.6396 & 0.6340 \\
\hline 14 & 0.6888 & 0.6830 \\
\hline 15 & 0.7381 & 0.7320 \\
\hline 16 & 0.7872 & 0.7810 \\
\hline 17 & 0.8364 & 0.8300 \\
\hline 18 & 0.8523 & 0.8790 \\
\hline 19 & 0.9348 & 0.9280 \\
\hline 20 & 0.9841 & 0.9770 \\
\hline 21 & 1.0822 & 1.0260 \\
\hline 22 & 1.0821 & 1.0750 \\
\hline 23 & 1.1316 & 1.1240 \\
\hline 24 & 1.1808 & 1.1730 \\
\hline 25 & 1.2341 & 1.2220 \\
\hline 26 & 1.2792 & 1.2710 \\
\hline 27 & 1.3284 & 1.3200 \\
\hline 28 & 1.3776 & 1.3690 \\
\hline 29 & 1.4268 & 1.4180 \\
\hline 30 & 1.4761 & 1.4670 \\
\hline 31 & 1.5252 & 1.5160 \\
\hline 32 & 1.5744 & 1.5650 \\
\hline 33 & 1.6236 & 1.6140 \\
\hline 34 & 1.6778 & 1.6630 \\
\hline 35 & 1.7221 & 1.7120 \\
\hline 36 & 1.7712 & 1.7610 \\
\hline 37 & 1.8204 & 1.8100 \\
\hline 38 & 1.8696 & 1.8590 \\
\hline 39 & 1.9188 & 1.9080 \\
\hline 40 & 1.9681 & 1.9570 \\
\hline
\end{tabular}


Table 3: Comparison of predictive and measured values of void ratio at different depth.

\begin{tabular}{|c|c|c|}
\hline Depth [M] & $\begin{array}{c}\text { Predictive Void Ratio } \\
\text { Values }\end{array}$ & $\begin{array}{c}\text { Experimental Values for Void } \\
\text { Ratio }\end{array}$ \\
\hline 0.2 & 0.00984 & 0.010002 \\
\hline 0.4 & 0.0197 & 0.020008 \\
\hline 0.6 & 0.0295 & 0.030018 \\
\hline 0.8 & 0.0394 & 0.040032 \\
\hline 1 & 0.049 & 0.05005 \\
\hline 1.2 & 0.059 & 0.060072 \\
\hline 1.4 & 0.069 & 0.070098 \\
\hline 1.6 & 0.0788 & 0.080128 \\
\hline 1.8 & 0.0886 & 0.090162 \\
\hline 2 & 0.098 & 0.1002 \\
\hline 2.2 & 0.11 & 0.110242 \\
\hline 2.4 & 0.12 & 0.120288 \\
\hline 2.6 & 0.13 & 0.130338 \\
\hline 2.8 & 0.14 & 0.140392 \\
\hline 3 & 0.15 & 0.15045 \\
\hline 3.2 & 0.16 & 0.160512 \\
\hline 3.4 & 0.17 & 0.170578 \\
\hline 3.6 & 0.18 & 0.180648 \\
\hline 3.8 & 0.19 & 0.190722 \\
\hline 4 & 0.2 & 0.2008 \\
\hline 4.2 & 0.21 & 0.210882 \\
\hline 4.4 & 0.22 & 0.220968 \\
\hline 4.6 & 0.23 & 0.231058 \\
\hline 4.8 & 0.24 & 0.241152 \\
\hline 5 & 0.25 & 0.25125 \\
\hline
\end{tabular}

Table 5: Predictive values of void ratio at different depths.

\begin{tabular}{|c|l|}
\hline Depth [M] & Predictive Void Ratio Values \\
\hline 3 & 0.147 \\
\hline 6 & 0.294 \\
\hline 9 & 0.441 \\
\hline 12 & 0.589 \\
\hline 15 & 0.736 \\
\hline 18 & 0.883 \\
\hline 21 & 1.031 \\
\hline 24 & 1.178 \\
\hline 27 & 1.325 \\
\hline 30 & 1.437 \\
\hline 33 & 1.621 \\
\hline 36 & 1.767 \\
\hline 39 & 1.914 \\
\hline 42 & 2.062 \\
\hline
\end{tabular}

Table 4: Predictive values of void ratio at different depths.

\begin{tabular}{|c|c|}
\hline Depth [M] & Predictive Void Ratio Values \\
\hline 0.2 & 0.00984 \\
\hline 0.4 & 0.0197 \\
\hline 0.6 & 0.0295 \\
\hline 0.8 & 0.0394 \\
\hline 1 & 0.049 \\
\hline 1.2 & 0.059 \\
\hline 1.4 & 0.069 \\
\hline 1.6 & 0.0788 \\
\hline 1.8 & 0.0886 \\
\hline 2 & 0.098 \\
\hline 2.2 & 0.11 \\
\hline 2.4 & 0.12 \\
\hline 2.6 & 0.13 \\
\hline 2.8 & 0.14 \\
\hline 3 & 0.15 \\
\hline 3.2 & 0.16 \\
\hline 3.4 & 0.17 \\
\hline 3.6 & 0.18 \\
\hline 3.8 & 0.19 \\
\hline 4 & 0.2 \\
\hline 4.2 & 0.21 \\
\hline 4.4 & 0.22 \\
\hline 4.6 & 0.23 \\
\hline 4.8 & 0.24 \\
\hline 5 & 0.25 \\
\hline
\end{tabular}




\begin{tabular}{|l|l|}
\hline 45 & 2.209 \\
\hline 48 & 2.356 \\
\hline 51 & 2.504 \\
\hline 54 & 2.651 \\
\hline 57 & 2.798 \\
\hline 60 & 2.946 \\
\hline
\end{tabular}

Table 6: Comparison of predictive and measured values of void ratio at different depth.

\begin{tabular}{|c|c|c|}
\hline Depth [M] & Predictive Void Ratio Values & Experimental Values for Void Ratio \\
\hline 3 & 0.147 & 0.145 \\
\hline 6 & 0.294 & 0.292 \\
\hline 9 & 0.441 & 0.439 \\
\hline 12 & 0.589 & 0.586 \\
\hline 15 & 0.736 & 0.733 \\
\hline 18 & 0.883 & 0.881 \\
\hline 21 & 1.031 & 1.027 \\
\hline 24 & 1.178 & 1.175 \\
\hline 27 & 1.325 & 1.322 \\
\hline 30 & 1.437 & 1.435 \\
\hline 33 & 1.621 & 1.615 \\
\hline 36 & 1.767 & 1.765 \\
\hline 39 & 1.914 & 1.912 \\
\hline 42 & 2.062 & 2.059 \\
\hline 45 & 2.209 & 2.207 \\
\hline 48 & 2.356 & 2.354 \\
\hline 51 & 2.504 & 2.502 \\
\hline 54 & 2.651 & 2.649 \\
\hline 57 & 2.798 & 2.796 \\
\hline 60 & 2.946 & 2.944 \\
\hline
\end{tabular}

Table 7: Comparison of predictive and measured values of void ratio at different depth.

\begin{tabular}{|c|c|c|}
\hline Depth [M] & Predictive Void Ratio Values & Experimental Values for Void Ratio \\
\hline 3 & 0.012 & 0.011 \\
\hline 6 & 0.025 & 0.023 \\
\hline 9 & 0.037 & 0.047 \\
\hline 12 & 0.051 & 0.059 \\
\hline 15 & 0.063 & 0.071 \\
\hline 18 & 0.078 & 0.083 \\
\hline 21 & 0.088 & 0.095 \\
\hline 24 & 0.101 & 0.107 \\
\hline 27 & 0.111 & 0.119 \\
\hline 30 & 0.121 & 0.131 \\
\hline 33 & 0.132 & 0.143 \\
\hline 36 & 0.151 & 0.155 \\
\hline 39 & 0.161 & 0.167 \\
\hline 42 & 0.171 & 0.179 \\
\hline 45 & 0.181 & \\
\hline
\end{tabular}




\begin{tabular}{|l|l|l|}
\hline 48 & 0.201 & 0.191 \\
\hline 51 & 0.211 & 0.203 \\
\hline 54 & 0.222 & 0.227 \\
\hline 57 & 0.241 & 0.239 \\
\hline 60 & 0.251 & 0.251 \\
\hline 63 & 0.261 & 0.263 \\
\hline 66 & 0.281 & 0.275 \\
\hline 69 & 0.291 & 0.287 \\
\hline 72 & 0.301 & 0.299 \\
\hline 75 & 0.311 & 0.311 \\
\hline 78 & 0.322 & 0.323 \\
\hline 81 & 0.344 & 0.335 \\
\hline 84 & 0.355 & 0.347 \\
\hline 87 & 0.361 & 0.359 \\
\hline 90 & 0.371 & 0.371 \\
\hline 93 & 0.391 & 0.383 \\
\hline 96 & 0.401 & 0.395 \\
\hline 99 & 0.411 & 0.399 \\
\hline 100 & 0.421 & \\
\hline
\end{tabular}

Table 8: Comparison of predictive and measured values of void ratio at different depth.

\begin{tabular}{|c|c|c|}
\hline Depth [M] & Predictive Void Ratio Values & Experimental Values for Void Ratio \\
\hline 3 & 0.012 & 0.0120063 \\
\hline 6 & 0.025 & 0.0240252 \\
\hline 9 & 0.037 & 0.0360567 \\
\hline 12 & 0.051 & 0.0481008 \\
\hline 15 & 0.063 & 0.0601575 \\
\hline 18 & 0.078 & 0.0722268 \\
\hline 21 & 0.088 & 0.0843087 \\
\hline 24 & 0.101 & 0.0964032 \\
\hline 27 & 0.111 & 0.1085103 \\
\hline 30 & 0.121 & 0.12063 \\
\hline 33 & 0.132 & 0.1327623 \\
\hline 36 & 0.151 & 0.1449072 \\
\hline 39 & 0.161 & 0.1570647 \\
\hline 42 & 0.171 & 0.1692348 \\
\hline 45 & 0.181 & 0.1814175 \\
\hline 48 & 0.201 & 0.1936128 \\
\hline 51 & 0.211 & 0.2058207 \\
\hline 54 & 0.222 & 0.2180412 \\
\hline 57 & 0.241 & 0.2302743 \\
\hline 60 & 0.251 & 0.24252 \\
\hline 63 & 0.261 & 0.2547783 \\
\hline 66 & 0.281 & 0.2670492 \\
\hline 69 & 0.291 & 0.2793327 \\
\hline 72 & 0.301 & 0.2916288 \\
\hline
\end{tabular}




\begin{tabular}{|c|c|c|}
\hline 75 & 0.311 & 0.3039375 \\
\hline 78 & 0.322 & 0.3162588 \\
\hline 81 & 0.344 & 0.3285927 \\
\hline 84 & 0.355 & 0.3409392 \\
\hline 87 & 0.361 & 0.3532983 \\
\hline 90 & 0.371 & 0.36567 \\
\hline 93 & 0.391 & 0.3780543 \\
\hline 96 & 0.401 & 0.3904512 \\
\hline 99 & 0.411 & 0.4028607 \\
\hline
\end{tabular}

Table 9: Comparison of predictive and measured values of void ratio at different depth.

\begin{tabular}{|c|c|c|}
\hline Depth [M] & Predictive Void Ratio Values & Experimental Values for Void Ratio \\
\hline 3 & 0.147 & 0.144081 \\
\hline 6 & 0.294 & 0.288324 \\
\hline 9 & 0.441 & 0.432729 \\
\hline 12 & 0.589 & 0.577296 \\
\hline 15 & 0.736 & 0.722025 \\
\hline 18 & 0.883 & 0.866916 \\
\hline 21 & 1.031 & 1.011969 \\
\hline 24 & 1.178 & 1.157184 \\
\hline 27 & 1.325 & 1.302561 \\
\hline 30 & 1.437 & 1.4481 \\
\hline 33 & 1.621 & 1.593801 \\
\hline 36 & 1.767 & 1.739664 \\
\hline 39 & 1.914 & 1.885689 \\
\hline 42 & 2.062 & 2.031876 \\
\hline 45 & 2.209 & 2.178225 \\
\hline 48 & 2.356 & 2.324736 \\
\hline 51 & 2.504 & 2.471409 \\
\hline 54 & 2.651 & 2.618244 \\
\hline 57 & 2.798 & 2.765241 \\
\hline 60 & 2.946 & 2.9124 \\
\hline
\end{tabular}

Table 10: Comparison of predictive and measured values of void ratio at different depth.

\begin{tabular}{|c|c|c|}
\hline Depth [M] & Predictive Void Ratio Values & Experimental Values for Void Ratio \\
\hline 1 & 0.0460 & 0.046 \\
\hline 2 & 0.0950 & 0.095 \\
\hline 3 & 0.1440 & 0.144 \\
\hline 4 & 0.1930 & 0.193 \\
\hline 5 & 0.2420 & 0.291 \\
\hline 6 & 0.2910 & 0.34 \\
\hline 7 & 0.3400 & 0.389 \\
\hline 9 & 0.3890 & 0.438 \\
\hline 10 & 0.4380 & 0.487 \\
\hline
\end{tabular}




\begin{tabular}{|c|c|c|}
\hline 11 & 0.5360 & 0.536 \\
\hline 12 & 0.5850 & 0.585 \\
\hline 13 & 0.6340 & 0.634 \\
\hline 14 & 0.6830 & 0.683 \\
\hline 15 & 0.7320 & 0.732 \\
\hline 16 & 0.7810 & 0.781 \\
\hline 17 & 0.8300 & 0.83 \\
\hline 18 & 0.8790 & 0.879 \\
\hline 19 & 0.9280 & 0.928 \\
\hline 20 & 0.9770 & 0.977 \\
\hline 21 & 1.0260 & 1.026 \\
\hline 22 & 1.0750 & 1.075 \\
\hline 23 & 1.1240 & 1.124 \\
\hline 24 & 1.1730 & 1.173 \\
\hline 25 & 1.2220 & 1.222 \\
\hline 26 & 1.2710 & 1.271 \\
\hline 27 & 1.3200 & 1.32 \\
\hline 28 & 1.3690 & 1.369 \\
\hline 29 & 1.4180 & 1.418 \\
\hline 30 & 1.4670 & 1.467 \\
\hline 31 & 1.5160 & 1.516 \\
\hline 32 & 1.5650 & 1.565 \\
\hline 33 & 1.6140 & 1.614 \\
\hline 34 & 1.6630 & 1.663 \\
\hline 35 & 1.7120 & 1.712 \\
\hline 36 & 1.7610 & 1.761 \\
\hline 37 & 1.8100 & 1.81 \\
\hline 38 & 1.8590 & 1.859 \\
\hline 39 & 1.9080 & 1.908 \\
\hline 40 & 1.9570 & 1.957 \\
\hline
\end{tabular}

\section{Conclusion}

The prediction of void ratios for silty and peat soil formation was to determine the heterogeneity of void ratios in peat and silty depositions under the influences of hydraulic conductivities and porosities in silty and peat sand depositions. The study tries to predict the structural deposition of silty and peat through their disintegration from predominant porous rock in deltaic environment, from the graphical representations, it was observed that the structures of the formations experiences linear depositions from the made soil to peat soil. Void ratios were in heterogeneity in exponential setting observed from graphical representations, this implies that the litho structures were influenced by the level of disintegration in the porous rock under the influences from variations of porosities and hydraulic conductivities, the derived solution were subjected to simulation, the validation generated favourable fits, these explain the void ratios within silty and peat soil depositions in deltaic environment. The basic principles in engineering properties of soil mechanics has been developed applying this analytical or deterministic modelling techniques. This can be applied to determine void ratios in settlements or any other design of foundation system.

\section{References}

1. Thevanayagam S (1997) Dielectric dispersion of porous media as a fractal phenomenon. J of Applied Physics 82(5): 2538-2547.

2. Thevanayagam S (1998) Effect of fines and confining stress on undrained shear strength of silty sands. J Geotech Geoenviron Eng Div 124(6): 479-491.

3. Mostefa B, Hanifi M, Ahmed A, Noureddine D, Tom S (2011) Undrained shear strength of sand-silt mixture: Effect of intergranular void ratio and other parameters. KSCE Journal of Civil Engineering 15(8): 1335-1342.

4. Zlatovic S, Ishihara K (1995) On the influence of non-plastic fines on residual strength. Proc. of the first Int Conf on Earthquake Geotech Eng, Tokyo, pp. 14-16.

5. Lade PV, Yamamuro JA (1997) Effects of non-plastic fines on static liquefaction of sands. Canadian Geotech J 34(6): 918-928.

6. Amini F, Qi GZ (2000) Liquefaction testing of stratified silty sands. J of Geotech Geoenviron Eng Proc 26(3): 208-217. 
7. Naeini SA, Baziar MH (2004) Effect of fines content on steady-state strength of mixed and layered samples of a sand. Soil Dyna and Earth Eng 3: 181-187.

8. Eluozo SN, Ode T (2015) Mathematical model to predict compression index of uniform loose sand in coastal area of Degema, rivers state of Nigeria. International Journal of Advance Research in Engineering and Technology 6(12): 86-103.

9. Eluozo SN, Ode T (2015) Mathematical to monitor stiff clay compression index in wet land area of Degema. International Journal of Advance Research in Engineering and Technology 6(12): 59-72.

10. Ode T, Eluozo SN (2016) Predictive model on compressive strength of concrete made with locally 3/8 Gravel from different water cement ratios and curing age. International Journal of Scientific and Engineering Research 7(1): 1528-1551.

11. Ode T, Eluozo SN (2016) Model prediction to monitor the rate of water absorption of concrete pressured by variation of time and water cement ratios. International Journal of Scientific and Engineering Research 7(1): 1514-1527

12. Ode T, Eluozo SN (2016) Calibrating the density of concrete from washed and unwashed locally $3 / 8$ gravel material at various curing age. International Journal of Scientific and Engineering Research 7(1): 15141552 .

13. Thevanayagam S, Mohan S (2000) Inter-granular state variables and stress-strain behaviour of silty sands. Geotechnique 50(1): 1-23.

14. Thevanayagam S, Ravishankar K, Mohan S (1997) Effects of fines on monotonic undrained shear strength of sandy soils. AST Geotech Testing J 20(1): 394-406
15. Ode T, Eluozo SN (2016) Compressive strength calibration of washed and unwashed locally occurring 3/8 gravel from various water cement ratios and curing age. International Journal Engineering and General Science 4(1): 462-483.

16. Ode T, Eluozo SN (2016) Predictive model to monitor variation of concrete density influenced by various grade from locally 3/8 gravel at different curing time. International Journal Engineering and General Science 4(1): 502-522.

17. Ode T, Eluozo SN (2016) Predictive model to monitor vitiation of stress -strain relationship of 3/8 gravel concrete with water cement ration [0.45] at different load. International Journal Engineering and General Science 4(1): 409-418.

18. Monkul MM (2005) Influence of inter-granular void ratio on one dimensional compression, M. Sc. Thesis, Dokuz Eylul University, Izmir, Turkey.

19. Eluozo SN, Ode T (2016) Modeling and simulation on velocity and permeability to predict bacillus on lag phase in predominant lateritic and silty formation in coastal area of Abonnema, Niger delta of Nigeria. International Journal of Civil Engineering and Technology 7(1): 304-314.

20. Baziar MH, Dobry R (1995) Residual strength and large-deformation potential of loose silty sands. J of Geotech Eng 121: 896-906.

21. Ladd RS (1978) Preparing test specimen using under compaction. Geotech Testing J 1(1): 16-23.

22. Thevanayagam S, Nesarajah S (1998) Fractal model for flow through saturated soil. Journal of Geotechnical and Geoenvironmental Engineering 124(1): 53-66.

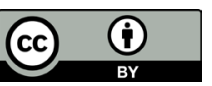

Creative Commons Attribution 4.0

International License

For possible submissions Click Here

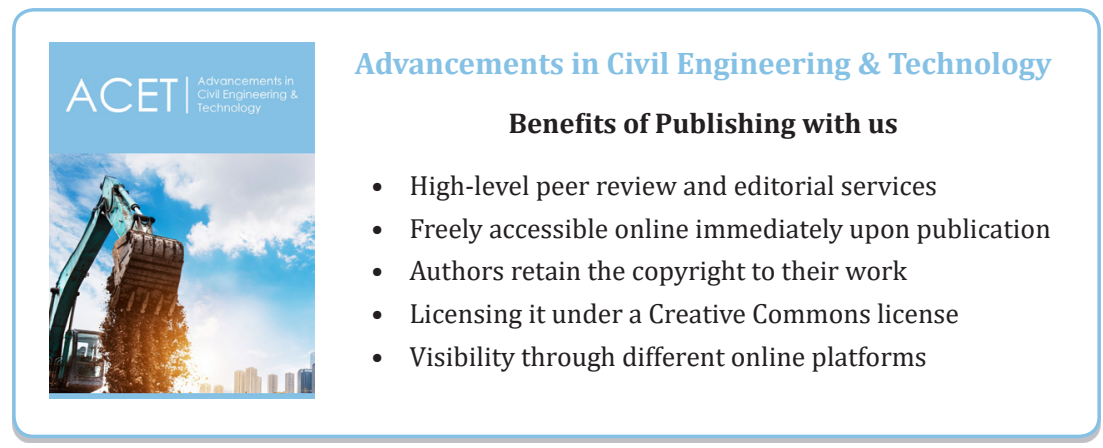

